\title{
Time-to-treatment and infarct size in STEMI patients undergoing primary angioplasty
}

\author{
Giuseppe De Luca ${ }^{\text {a,*}}{ }^{*}$, Guido Parodi ${ }^{\text {b }}$, Roberto Sciagrà ${ }^{\mathrm{c}}$, Francesco Venditti ${ }^{\mathrm{b}}$, Benedetta Bellandi ${ }^{\mathrm{b}}$, \\ Ruben Vergara ${ }^{\text {b }}$, Angela Migliorini ${ }^{\text {b }}$, Renato Valenti ${ }^{\text {b }}$, David Antoniucci ${ }^{\text {b }}$ \\ a Division of Cardiology, "Maggiore della Carità" Hospital, Eastern Piedmont University, Novara, Italy \\ ${ }^{\mathrm{b}}$ Division of Cardiology Careggi Hospital, Florence, Italy \\ c Nuclear Medicine Unity, University of Florence, Florence, Italy
}

\section{A R T I C L E I N F O}

\section{Article history:}

Received 28 August 2011

Received in revised form 5 March 2012

Accepted 10 April 2012

Available online $\mathrm{xxxx}$

\section{Keywords:}

Primary angioplasty

Infarct size

Time-to-treatment

\begin{abstract}
A B S T R A C T
Background: Several reports have shown that in patient with ST-segment elevation acute myocardial infarction (STEMI) longer ischemia time is associated with impaired reperfusion and higher mortality. However, there is still some doubts with regards time to reperfusion role in patients treated with primary percutaneous coronary intervention (PCI). Therefore, the aim of the current study was to evaluate the impact of time-totreatment on infarct size as evaluated by myocardial scintigraphy in a large cohort of STEMI patients undergoing primary $\mathrm{PCI}$.

Methods: Our population is represented by 830 STEMI patients undergoing primary PCI. Infarct size was evaluated at 30 days by technetium-99m-sestamibi.

Results: Time-to-treatment was significantly associated with age and dyslipidemia. Time-to-treatment linearly affected the rate of postprocedural TIMI 3 flow $(\mathrm{p}<0.0001)$ and scintigraphic infarct size $(\mathrm{p}<0.001)$. The impact of time-to-treatment on infarct size persisted in the analysis restricted to patients with postpocedural TIMI 3 flow, and after correction for confounding factors such as age, dyslipidemia, postprocedural TIMI 3 flow (OR $[95 \% \mathrm{CI}]=1.26[1.14-1.39], \mathrm{p}<0.001)$.

Conclusions: This study shows in a large population of STEMI patients undergoing primary PCI that time-totreatment is linearly associated with infarct size.
\end{abstract}

(C) 2012 Elsevier Ireland Ltd. All rights reserved.

\section{Introduction}

Availability of pharmacologic and mechanical reperfusion therapies has significantly reduced cardiac mortality among ST-segment elevation acute myocardial infarction (STEMI) patients [1-11]. However, even though primary angioplasty has been shown to be superior to thrombolysis, mainly due to a larger success in epicardial recanalization, a suboptimal myocardial reperfusion is observed in a still relevant percentage of patients $[12,13]$. A clear relationship between mortality and time delay from symptom-onset to treatment has been demonstrated in patients with STEMI treated by thrombolysis $[14,15]$. Some studies have suggested a prognostic impact of timeto-treatment in STEMI patients undergoing primary angioplasty [16-21]. However, few data have been reported in terms of infarct size. Moreover, myocardial perfusion scintigraphy has been widely used to accurately assess infarct size in clinical trials and in current medical practice. Therefore, the aim of the current study was to evaluate the influence of symptom-onset-to-balloon time on infarct size as evaluated by technetium-99m-sestamibi in a large cohort of patients with STEMI treated by primary angioplasty.

\footnotetext{
* Corresponding author. Tel.: + 3903213733141 ; fax: + 3903213733407. E-mail address: g.deluca@diagram-zwolle.nl (G. De Luca).
}

\section{Materials and methods}

Our population is represented by 830 STEMI patients treated by primary angioplasty undergoing evaluation of infarct size at 30 days after the intervention. All patients were admitted within $12 \mathrm{~h}$ from symptom onset. All patients received aspirin ( $500 \mathrm{mg}$ intravenously), heparin (60 IU/kg IV) (both administrated out-of-hospital if patients were transported by an ambulance otherwise at hospital admission after diagnosis) and clopidogrel (at hospital admission after diagnosis). The decision to provide Gp IIb-IIla inhibitors was left at the discretion of the operator in the cath lab. All patients were on dual oral antiplatelet therapy (aspirin and clopidogrel or ticlopidine) for at least 4 weeks after stent implantation. Ischemia time was defined as the interval between symptoms onset to first balloon inflation. The authors of this manuscript have certified that they comply with the Principles of Ethical Publishing in the International Journal of Cardiology [49].

\subsection{Coronary angiography and mechanical revascularization}

Selective coronary angiography was performed in multiple projections before mechanical reperfusion. Immediately after diagnostic angiography, angioplasty with stenting of the infarct-related vessel was performed using standard material. Successful primary percutaneous coronary intervention was defined as Thrombolysis In Myocardial Infarction (TIMI) grade 3 coronary flow in the treated vessel with a residual stenosis $<20 \%[22]$.

\subsection{Infarct size assessment}

As previously described [23], gated single-photon emission computed tomography (SPECT) acquisition began 60 min after technetium-99m-sestamibi injection (740 MBq), using a double-head gamma-camera equipped with high-resolution collimators, $180^{\circ}$ 
rotation arc, 32 projections, 60 s/projection, 8 frames/heart cycle and $64 \times 64$ matrices. The studies were reconstructed using filtered back-projection without attenuation or scatter correction and realigned along the heart axis. Perfusion defects were quantified as percentage of LV wall, with the defect threshold set at $60 \%$ of peak uptake [24].

\subsection{Statistical analysis}

Statistical analysis was performed with the SPSS 15.0 statistical package. Continuous data were expressed as mean $\pm \mathrm{SD}$ and categorical data as percentage. The ANOVA test was appropriately used for continuous variables. The chi-square test or the Fisher's exact test was used for categorical variables. Patients were divided according to ischemia time ( $<2 \mathrm{~h}, 2-3 \mathrm{~h}, 3-4 \mathrm{~h}, 4-5 \mathrm{~h}, 5-6 \mathrm{~h}$, and $\geq 6 \mathrm{~h}$ ). Multiple logistic regression analysis was used to evaluate the impact of ischemia time on infarct size after adjustment for significant $(\mathrm{p}<0.05)$ confounding baseline characteristics.

\section{Results}

Patients characteristics are shown in Tables 1 and 2. Time-totreatment was significantly associated with age $(p<0.001)$ and dyslipidemia $(p<0.001)$. No differences were observed in terms of other clinical characteristics. Time-to-treatment inversely affected the rate of postprocedural TIMI 3 flow $(\mathrm{p}<0.0001)$ (Adjusted OR $[95 \% \mathrm{CI}]=0.69[0.59-0.81], \mathrm{p}<0.001)$.

As shown in Fig. 1, time-to-treatment was linearly related to infarct size. Similar results were observed when infarct size was dichotomized according to the median value (OR $[95 \% \mathrm{CI}]=1.25$ [1.13-1.37], $\mathrm{p}<0.001$ ) (Fig. 2). These data were confirmed even in the analysis restricted to patients with postprocedural TIMI 3 flow (Figs. 1B and 2B) and after the exclusion of patients with previous MI $(n=34)$. Fig. 3 shows the impact of ischemia time as continuous function on infarct size $\left(R^{2}=0.0 .14\right.$, beta $\left.=0.015, p<0.001\right)$. Identical results were found after the exclusion of patients with previous MI $\left(\mathrm{R}^{2}=0.0 .14\right.$, beta $\left.=0.015, \mathrm{p}<0.001\right)$. Therefore, infarct size increased by $0.9 \%$ per each hour delay to treatment. Subanalyses conducted according to a threshold of ischemia time of $3 \mathrm{~h}$ did not show any heterogeneity in any of the analyzed subgroups according to age, sex, diabetes, preprocedural TIMI flow, anterior infarct location and multivessel disease (Fig. 4). By multiple regression analysis, time-totreatment significantly affected infarct size even after correction for clinical (age and dyslipidemia) and procedural (postprocedural TIMI 3 flow) characteristics (OR [95\% CI] $=1.26$ [1.14-1.39], $\mathrm{p}<0.001$ ).

\section{Discussion}

This is one of the largest study conducted so far evaluating the impact of time-to-treatment on scintigraphic infarct size in STEMI patients undergoing primary PCI. We found that time-to-treatment was linearly and independently associated with infarct size.

Primary angioplasty has been shown to provide mortality benefits as compared to thrombolysis. However, despite optimal epicardial recanalization, suboptimal reperfusion and therefore larger infarct size is observed in a relatively large proportion of patients, especially in those at high-risk undergoing mechanical reperfusion [25,26]. Despite the demonstrated prognostic role of time to therapy and its linear association with outcome in patients with STEMI treated by thrombolysis $[14,15]$, there is still doubt with regard to its role in patients treated with primary angioplasty [16-21].

Brodie et al. [16] observed a better outcome among patients undergoing primary angioplasty within $2 \mathrm{~h}$ from symptom onset, whereas a relatively stable mortality rate was observed between 2 and $12 \mathrm{~h}$. Consistent with these data, Zijlstra et al. [15], in a recent pooled-analysis of several randomized trials comparing primary angioplasty and thrombolysis, found a direct relationship between time from symptom onset to treatment only in patients treated by thrombolysis, but not by primary angioplasty. Consisting with these data, the Munich group has shown a significant impact of time-totreatment on infarct size only with thrombolysis but not with primary angioplasty [27]. However, the same group has subsequently observed a significant impact of preprocedural TIMI 3 flow (surrogate marker of ischemic time) on scintigraphic infarct size [28]. In fact, a similar impact of preprocedural TIMI flow was observed also in other studies [29-31].

Conversely, several additional reports have shown the impact if ischemia time on mortality. Cannon et al. [18] in a cohort of 27,080 patients undergoing primary angioplasty found door-to-balloon time to be associated with mortality. These findings were confirmed by Antoniucci et al. [19] in high-risk patients. The Zwolle group analyzed the impact of time-to-treatment as a continuous function in a population of 1791 STEMI patients [20]. After correction for baseline confounding factors, they observed that every $30 \mathrm{~min}$ of delay to treatment was associated with $7.5 \%$ increase in the relative risk of 1-year mortality. In another analysis confined to patients undergoing transferring for primary angioplasty, De Luca et al. [32] found that interhospital delay was significantly associated with mortality.

In the DANAMI-2 trial, Maeng et al. [33] found that time-totreatment significantly affected predischarge ejection fraction and 3-year mortality. Data from a recent updated meta-analysis of trials comparing primary angioplasty vs. thrombolysis [34], have shown similar impact of time-to-treatment for both reperfusion strategies. Several additional studies have been conducted to contribute to explain the prognostic role of ischemia time in primary angioplasty. De Luca et al. [35] showed in a population of 1072 STEMI patients that time-to-treatment had a significant impact on myocardial perfusion (as evaluated by myocardial blush and ST-segment resolution), enzymatic infarct size and predischarge ejection fraction. Interestingly, these results were confirmed in the analysis restricted to patients with postprocedural TIMI 3 flow. Thus, even though primary angioplasty is able to restore TIMI 3 flow independently from the time of treatment, this cannot abrogate the deleterious effects of ischemia time on myocardial necrosis and perfusion. More recently, data from the EMERALD trial [36] have shown a clear relationship between time-to-treatment, myocardial perfusion and infarct size analyzed by

Table 1

Baseline demographic and clinical characteristics according to time-to-treatment.

\begin{tabular}{|c|c|c|c|c|c|c|c|}
\hline \multirow[b]{2}{*}{ Variable } & \multicolumn{7}{|c|}{ Ischemia time (hours) } \\
\hline & $<2(\mathrm{n}=106)$ & $2-3(n=228)$ & $3-4(n=212)$ & $4-5(n=126)$ & $5-6(n=72)$ & $>6(n=77)$ & $\mathrm{p}$ Value trend \\
\hline Age (years) & $62.4 \pm 11.1$ & $62.6 \pm 11.2$ & $63.5 \pm 12.6$ & $65.6 \pm 11.7$ & $65.8 \pm 12.5$ & $66.2 \pm 13.1$ & $<0.001$ \\
\hline Female gender (\%) & 18.9 & 18.0 & 23.6 & 19.8 & 25 & 24.7 & 0.16 \\
\hline Smoking (\%) & 52.8 & 52.6 & 46.7 & 37.3 & 47.2 & 50.6 & 0.16 \\
\hline Diabetes (\%) & 10.4 & 13.2 & 14.2 & 20.6 & 9.7 & 13 & 0.51 \\
\hline Hypertension (\%) & 53.8 & 37.7 & 43.9 & 46.8 & 45.8 & 37.7 & 0.48 \\
\hline Dyslipidemia (\%) & 37.7 & 41.2 & 35.5 & 26.2 & 31.9 & 19.5 & $<0.001$ \\
\hline Preinfarction angina (\%) & 7.3 & 7.1 & 7.9 & 2.9 & 8.8 & 15.8 & 0.65 \\
\hline Previous MI (\%) & 3.8 & 3.9 & 5.2 & 4.8 & 1.4 & 2.6 & 0.51 \\
\hline Previous CABG (\%) & 0 & 0.4 & 1.9 & 0.8 & 1.4 & 0 & 0.7 \\
\hline Previous PTCA (\%) & 3.8 & 5.3 & 2.8 & 2.4 & 0 & 3.9 & 0.19 \\
\hline Cardiogenic shock (\%) & 6.6 & 1.8 & 6.6 & 3.2 & 2.8 & 2.6 & 0.095 \\
\hline
\end{tabular}


Table 2

Angiographic and procedural characteristics according to time-to-treatment.

\begin{tabular}{|c|c|c|c|c|c|c|c|}
\hline \multirow[b]{2}{*}{ Variable } & \multicolumn{7}{|c|}{ Ischemia time (hours) } \\
\hline & $<2(\mathrm{n}=106)$ & $2-3(n=228)$ & $3-4(n=212)$ & $4-5(n=126)$ & $5-6(n=72)$ & $>6(\mathrm{n}=77)$ & $\mathrm{p}$ Value trend \\
\hline Chronic occlusion (\%) & 3.6 & 4.3 & 7.7 & 5.8 & 2.9 & 0 & 0.795 \\
\hline Collateral circulation & & & & & & & 0.22 \\
\hline RENTROP $0(\%)$ & 96.4 & 88.9 & 88.7 & 87.0 & 85.7 & 90.0 & \\
\hline RENTROP 1 (\%) & 1.8 & 7.7 & 8.3 & 8.7 & 8.6 & 5.0 & \\
\hline RENTROP 2 (\%) & 1.8 & 2.6 & 2.3 & 4.3 & 5.7 & 0 & \\
\hline RENTROP 3 (\%) & 0 & 0.9 & 0.8 & 0 & 0 & 0 & \\
\hline Pre-procedural TIMI flow & & & & & & & 0.31 \\
\hline TIMI $0-1(\%)$ & 80.3 & 80.5 & 84.1 & 77.2 & 88.0 & 82.1 & \\
\hline TIMI $2(\%)$ & 12.8 & 9.8 & 7.3 & 13.2 & 7.2 & 13.7 & \\
\hline TIMI 3 (\%) & 6.8 & 9.8 & 8.6 & 9.6 & 4.8 & 4.2 & \\
\hline Infarct-related artery & & & & & & & 0.92 \\
\hline RCA (\%) & 41.0 & 45.2 & 46.8 & 47.1 & 48.2 & 44.8 & \\
\hline $\mathrm{CX}(\%)$ & 15.7 & 14.5 & 11.1 & 17.6 & 15.7 & 11.5 & \\
\hline Graft (\%) & 0 & 0 & 0.4 & 0 & 0 & 0 & \\
\hline LAD (\%) & 43.6 & 40.3 & 41.3 & 35.3 & 36.1 & 43.8 & \\
\hline LM $(\%)$ & 0 & 0 & 0.7 & 0 & 0 & 0 & \\
\hline Multivessel disease (\%) & 40.0 & 37.9 & 43.0 & 44.1 & 42.0 & 41.7 & 0.428 \\
\hline N. lesions & & & & & & & 0.27 \\
\hline $1(\%)$ & 76.9 & 79.8 & 77.9 & 72.8 & 80.7 & 69.8 & \\
\hline $2(\%)$ & 17.1 & 15 & 18.7 & 22.8 & 14.5 & 21.9 & \\
\hline $3(\%)$ & 5.1 & 4.0 & 3.0 & 3.7 & 3.6 & 7.3 & \\
\hline Abciximab (\%) & 98.3 & 91.1 & 87.2 & 86.8 & 85.5 & 94.8 & 0.13 \\
\hline Stenting $(\%)$ & 98.2 & 99.1 & 99.2 & 98.5 & 97.1 & 100 & 0.95 \\
\hline Thrombectomy (\%) & 39.6 & 43.8 & 40.5 & 39.7 & 47.2 & 46.7 & 0.6 \\
\hline $\operatorname{IABP}(\%)$ & 4.3 & 2.8 & 5.5 & 1.5 & 4.8 & 7.3 & 0.21 \\
\hline Post-procedural TIMI 3 flow (\%) & 95.7 & 93.9 & 95.7 & 86.7 & 85.5 & 80.0 & $<0.001$ \\
\hline
\end{tabular}

scintigraphy. Similar finding has been observed in a pooled analysis of 4 trials performed by Stone et al. [37], even though the impact was mostly observed within the first hours. A recent study conducted by Tarantini et al. [38] has evaluated the impact of time-to-treatment on infarct size, estimated by MRI. Supporting data by De Luca et al.

A

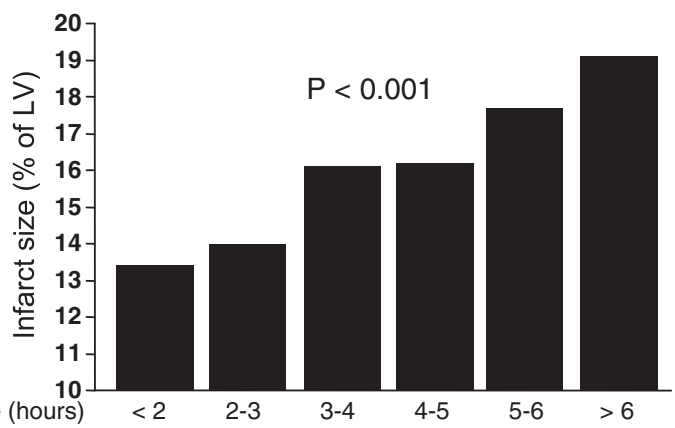

B

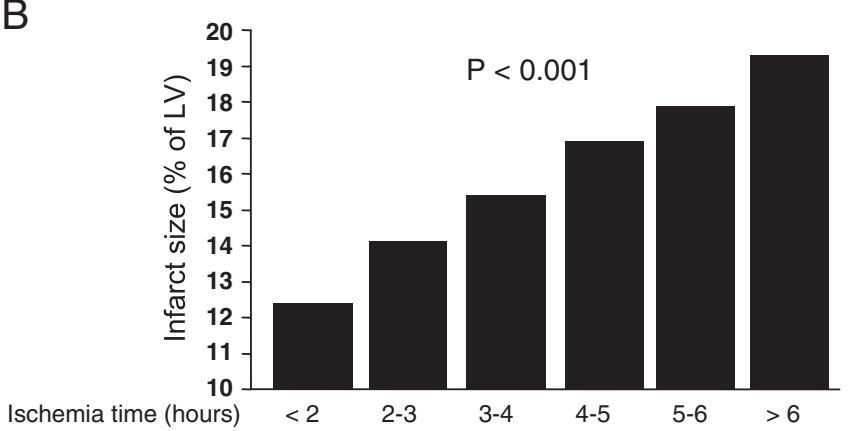

Fig. 1. Bar graph shows the significant relationship between ischemia time and scintigraphic infarct size in all population $(A)$, that was confirmed in the analysis restricted to patients with postprocedural TIMI 3 flow (B).
[20], they observed a significant increase in infarct size by every 30 min delay to treatment.

In our study, including 830 STEMI patients undergoing primary angioplasty, we found that infarct size, accurately assessed by myocardial perfusion scintigraphy, was linearly related to time-to-treatment. The relationship was observed even when restricted to patients with postprocedural TIMI 3 flow. In fact, the impact of time-to-treatment
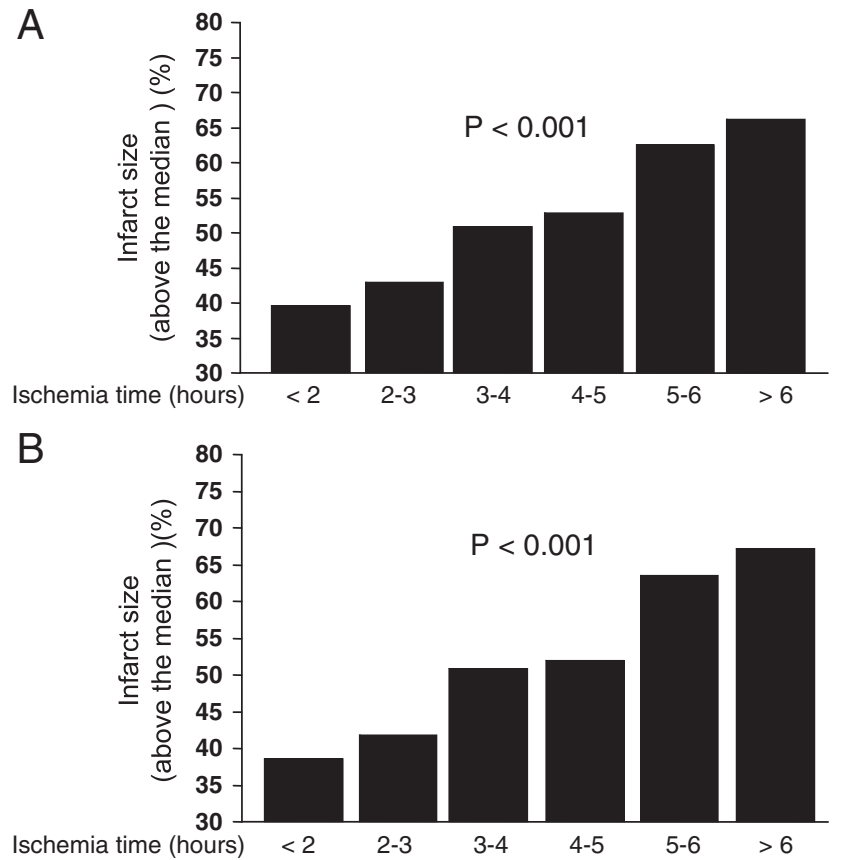

Fig. 2. Bar graph shows the significant relationship between ischemia time and scintigraphic infarct size (as above the median) in all population (A), that was confirmed in the analysis restricted to patients with postprocedural TIMI 3 flow (B). 


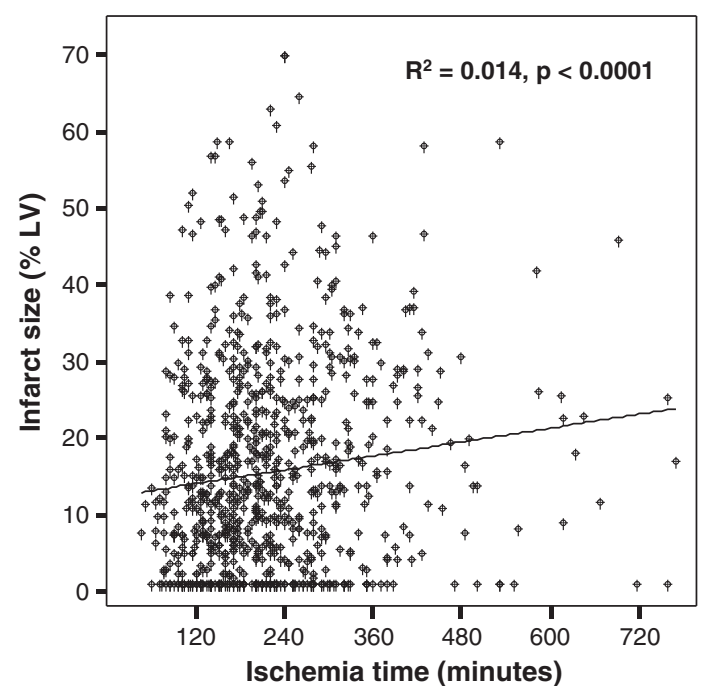

Fig. 3. Impact of ischemia time (in minutes on X-axis) on infarct size (as \% of left ventricle (LV) on Y-axis). $R^{2}$-values and $P$-values refer to the linear correlations.

on infarct size persisted after correction for confounding factors, such as age, dyslipidemia and postprocedural TIMI 3 flow.

All these data support the need to shorten ischemia time by early diagnosis and direct transportation to the cath lab. The experience in Zwolle showed that interhospital delay was an independent predictor of mortality [32]. Similarly, the Danish experience strongly demonstrated the importance and clinical impact on long-term mortality [39] and occurrence of heart failure [40] of health care organization and system delays. Several trials and meta-analysis have evaluated the role of pharmacological facilitation. Studies on facilitation with lythic therapy showed a significant increase in the risk of major bleeding complications and reinfarction [41,42], and therefore this strategy has been abandoned, whereas great attention has been paid to Gp IIb-IIIa inhibitors. A previous meta-analysis based on individual patients' data [10] showed that early abciximab, but not Eptifibatide and Tirofiban, was associated with significant benefits in mortality. These beneficial effects have been confirmed at long- term follow-up [43]. However, more recently high-dose bolus of tirofiban and double bolus of eptifibatide have been shown to provide more complete and faster inhibition of platelet aggregation and therefore larger benefits would be expected from these new dosages. The on-time-2 trial [44] investigated the benefits from early highdose tirofiban administration in the ambulance as compared to placebo, with significant benefits in preprocedural recanalization and STresolution. When the data were pooled with the pilot phase, there was a significant reduction in mortality. These beneficial effects have been confirmed in large registries [45]. Therefore despite the negative results of the largest randomized trials (FINESSE) [46], based on the demonstrated prognostic role of ischemia time, and the current evidence from randomized and registry data, early administration of Gp IIb-IIIa inhibitors may be considered, especially among high-risk patients.

\section{Study limitations}

We assessed the infarct size 1 month after the index infarction instead of at hospital discharge, as in the majority of previously published studies. On the other hand, this circumstance should be more effective in preventing interference of myocardial stunning with the extent of perfusion defects [47]. We did not performed routinely in all patients with coronary angiographic control before gated SPECT to allow the exclusion of infarct-related vessel restenosis. A potential bias of later presentation of patients with bigger infarcts seems unlikely, since there was no significant difference between study groups regarding the incidence of cardiogenic shock, anterior infarct location, resuscitation/intubation, and left bundle branch block at presentation. Only a minority of patients were treated with thrombectomy, with similar rates across time intervals. However, confirming the results of the JETSTENT trial [48], the use of thrombectomy did not affect infarct size $(11.9 \pm 10 \%$ vs. $13.1 \pm 11 \%, p=0.25)$. Finally, our data must be interpreted with the concept that ischemia time is just a piece of the puzzle. In fact, final infarct size is certainly influenced by aging, preprocedural TIMI flow, IRA location, and periprocedural factors such as ischemia reperfusion damage, distal atherothrombotic embolization, and no-reflow. Therefore, despite the relatively low $R$ square value, we strongly believe that the $0.9 \%$ increase in infarct size per each hour of ischemia time (as estimated by our coefficients)

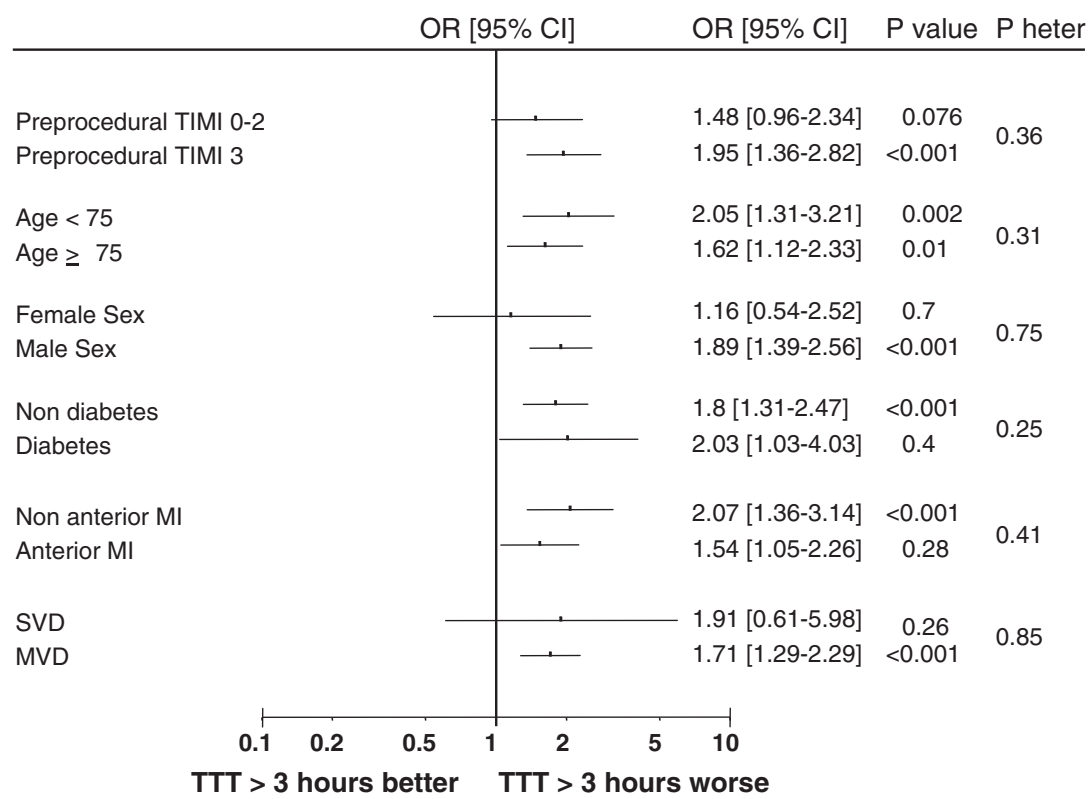

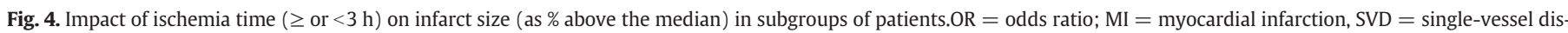
ease; MVD $=$ multivessel disease. 
is not only statistically ( $\mathrm{p}<0.0001$ ) but, in consideration of the above mentioned aspects and the fact that it is a modifiable variable, also clinically significant. In fact, the impact of ischemia time on infarct size is the explanation of the demonstrated effect of ischemia time on survival.

\section{Conclusions}

This study showed that among STEMI patients undergoing primary angioplasty, time-to-treatment is linearly and independently associated with scintigraphic infarct size. Therefore, all the attempts should be made in order to reduce ischemia time by making aware patients of heart attack symptoms and of prompt emergency system activation, direct transportation to the cath lab and potentially early pharmacological reperfusion.

\section{References}

[1] De Luca G, Cassetti E, Marino P. Percutaneous coronary intervention-related time delay, patient's risk profile, and survival benefits of primary angioplasty vs. lytic therapy in ST-segment elevation myocardial infarction. Am J Emerg Med 2009;27: 712-9.

[2] De Luca G, Biondi-Zoccai G, Marino P. Transferring patients with ST-segment elevation myocardial infarction for mechanical reperfusion: a meta-regression analysis of randomized trials. Ann Emerg Med 2008;52:665-76.

[3] Parodi G, Memisha G, Valenti R, et al. Five-year outcome after primary coronary intervention for acute ST elevation myocardial infarction: results from a single centre experience. Heart 2005;91:1541-4.

[4] Di Lorenzo E, Sauro R, Varricchio A, et al. Benefits of drug-eluting stents as compared to bare metal stent in ST-segment elevation myocardial infarction: four year results of the PaclitAxel or Sirolimus-Eluting stent vs bare metal stent in primary angiOplasty (PASEO) randomized trial. Am Heart J 2009 Oct;158(4):e43-50.

[5] De Luca G, Suryapranata H, Stone GW, et al. Abciximab as adjunctive therapy to reperfusion in acute ST-segment elevation myocardial infarction: a meta-analysis of randomized trials. JAMA 2005;293:1759-65.

[6] De Luca G, Cassetti E, Verdoia M, Marino P. Bivalirudin as compared to unfractionated heparin among patients undergoing coronary angioplasty: a meta-analysis of randomised trials. Thromb Haemost 2009;102:428-36.

[7] Antoniucci D, Migliorini A, Parodi G, et al. Abciximab-supported infarct artery stent implantation for acute myocardial infarction and long-term survival: a prospective, multicenter, randomized trial comparing infarct artery stenting plus abciximab with stenting alone. Circulation 2004;109:1704-6.

[8] De Luca G, Navarese E, Marino P. Risk profile and benefits from Gp IIb-IIla inhibitors among patients with ST-segment elevation myocardial infarction treated with primary angioplasty: a meta-regression analysis of randomized trials. Eu Heart J 2009;30:2705-13.

[9] De Luca G, Ucci G, Cassetti E, Marino P. Benefits from small molecule administration as compared with abciximab among patients with ST-segment elevation myocardial infarction treated with primary angioplasty: a meta-analysis. J Am Coll Cardiol 2009;53:1668-73.

[10] De Luca G, Gibson CM, Bellandi F, et al. Early glycoprotein IIb-IIla inhibitors in primary angioplasty (EGYPT) cooperation: an individual patient data meta-analysis. Heart 2008:94:1548-58.

[11] De Luca G, Dudek D, Sardella G, Marino P, Chevalier B, Zijlstra F. Adjunctive manual thrombectomy improves myocardial perfusion and mortality in patients undergoing primary percutaneous coronary intervention for ST-elevation myocardial infarction: a meta-analysis of randomized trials. Eur Heart J 2008;29:3002-10.

[12] De Luca G, Maas AC, Suryapranata H, et al. Prognostic significance of residual cumulative ST-segment deviation after mechanical reperfusion in patients with STsegment elevation myocardial infarction. Am Heart J 2005;150:1248-54.

[13] Parodi G, Valenti R, Carrabba N, et al. Long-term prognostic implications of nonoptimal primary angioplasty for acute myocardial infarction. Catheter Cardiovasc Interv 2006;68:50-5.

[14] Newby LK, Rutsch WR, Califf RM, et al. Time from symptom onset to treatment and outcomes after thrombolyitc therapy. J Am Coll Cardiol 1996;27:1646-55.

[15] Zijlstra F, Grines CL, Ellis S, et al. Clinical characteristics and outcome of patients with early $(<2 \mathrm{~h})$, intermediate $(2-4 \mathrm{~h})$ and late $(>4 \mathrm{~h})$ presentation treated by primary coronary angioplasty or thrombolytic therapy for acute myocardial infarction. Eur Heart J 2002;23:550-7.

[16] Brodie BR, Stuckey TD, Wall TC, et al. Importance of time to reperfusion for 30-day and late survival and recovery of left ventricular function after primary angioplasty for acute myocardial infarction. J Am Coll Cardiol 1998;32:1312-9.

[17] Berger PB, Ellis SG, Holmes DR et al. Relationship between delay in performing direct coronary angioplasty and early clinical outcome in patients with acute myocardial infarction: results from the Global Use of Strategies to Open Occluded Arteries in Acute Coronary Syndromes (GUSTO IIb) trial. Circulation 1999;100: 14-20.

[18] Cannon CP, Gibson CM, Lambrew CT, et al. Relationship of symptom-onset-toballoon time and door-to-balloon time with mortality in patients undergoing angioplasty for acute myocardial infarction. JAMA 2000;283:2941-7.
[19] Antoniucci D, Valenti R, Migliorini A, et al. Relation of time to treatment and mortality in patients with acute myocardial infarction undergoing primary coronary angioplasty. Am J Cardiol 2002;89:1248-52.

[20] De Luca G, Suryapranata H, Ottervanger JP, Antman EM. Time delay to treatment and mortality in primary angioplasty for acute myocardial infarction: every minute of delay counts. Circulation 2004;109:1223-5.

[21] De Luca G, Suryapranata H, Zijlstra F, et al. Symptom-onset-to-balloon time and mortality in patients with acute myocardial infarction treated by primary angioplasty. J Am Coll Cardiol 2003;42:991-7.

[22] The TIMI Study Group. The Thrombolysis in Myocardial Infarction (TIMI) trial: phase 1 findings. N Engl J Med 1985;312:932-6.

[23] Sciagrà R, Imperiale A, Antoniucci D, et al. Relationship of infarct size and severity versus left ventricular ejection fraction and volumes obtained from 99mTcsestamibi gated single-photon emission computed tomography in patients treated with primary percutaneous coronary intervention. Eur J Nucl Med Mol Imaging 2004;31:969-74.

[24] O'Connor MK, Hammel T, Gibbons RJ. In vitro validation of a simple tomographic technique for estimation of percentage myocardium at risk using methoxyisobutyl isonitrile technetium 99m (sestamibi). Eur J Nucl Med 1990;17:69-76.

[25] De Luca G, van't Hof AW, Ottervanger JP, et al. Ageing, impaired myocardial perfusion, and mortality in patients with ST-segment elevation myocardial infarction treated by primary angioplasty. Eur Heart J 2005;26:662-6.

[26] De Luca G, Gibson CM, Bellandi F, et al. Diabetes mellitus is associated with distal embolization, impaired myocardial perfusion, and higher mortality in patients with ST-segment elevation myocardial infarction treated with primary angioplasty and glycoprotein IIb-IIla inhibitors. Atherosclerosis 2009;207: 181-5.

[27] Schömig A, Ndrepepa G, Mehilli J, et al. Therapy-dependent influence of time-totreatment interval on myocardial salvage in patients with acute myocardial infarction treated with coronary artery stenting or thrombolysis. Circulation 2003; 108:1084-8

[28] Ndrepepa G, Kastrati A, Schwaiger M, et al. Relationship between residual blood flow in the infarct-related artery and scintigraphic infarct size, myocardial salvage, and functional recovery in patients with acute myocardial infarction. J Nucl Med 2005:46:1782-8.

[29] De Luca G, Ernst N, Zijlstra F, et al. Preprocedural TIMI flow and mortality in patients with acute myocardial infarction treated by primary angioplasty. J Am Coll Cardiol 2004:43:1363-7.

[30] De Luca G, Ernst N, van't Hof AW, et al. Preprocedural Thrombolysis in Myocardial Infarction (TIMI) flow significantly affects the extent of ST-segment resolution and myocardial blush in patients with acute anterior myocardial infarction treated by primary angioplasty. Am Heart J 2005;150:827-31.

[31] Leoncini M, Bellandi F, Sciagrà R, et al. Use of 99mTc-sestamibi gated SPECT to assess the influence of anterograde flow before primary coronary angioplasty on tissue salvage and functional recovery in acute myocardial infarction. Eur J Nucl Med Mol Imaging 2004;31:1378-85.

[32] De Luca G, Ernst N, Suryapranata H, et al. Relation of interhospital delay and mortality in patients with ST-segment elevation myocardial infarction transferred for primary coronary angioplasty. Am J Cardiol 2005;95:1361-3.

[33] Maeng M, Nielsen PH, Busk M, et al. DANAMI-2 Investigators. Time to treatment and three-year mortality after primary percutaneous coronary intervention for ST-segment elevation myocardial infarction - a DANish Trial in Acute Myocardial Infarction-2 (DANAMI-2) substudy. Am J Cardiol 2010;105:1528-34.

[34] Boersma E. The primary coronary angioplasty vs. thrombolysis group. Does time matter? A pooled analysis of randomized clinical trials comparing primary percutaneous coronary intervention and in-hospital fibrinolysis in acute myocardial infarction patients. Eur Heart J 2006;27:779-88.

[35] De Luca G, van't Hof AW, de Boer MJ, et al. Time-to-treatment significantly affects the extent of ST-segment resolution and myocardial blush in patients with acute myocardial infarction treated by primary angioplasty. Eur Heart J 2004;25:1009-13.

[36] Brodie BR, Webb J, Cox DA, et al. Impact of time to treatment on myocardial reperfusion and infarct size with primary percutaneous coronary intervention for acute myocardial infarction (from the EMERALD Trial). Am J Cardiol 2007;99: 1680-6.

[37] Stone GW, Dixon SR, Grines CL, et al. Predictors of infarct size after primary coronary angioplasty in acute myocardial infarction from pooled analysis from four contemporary trials. Am J Cardiol 2007;100:1370-5.

[38] Tarantini G, Cacciavillani L, Corbetti F, et al. Duration of ischemia is a major determinant of transmurality and severe microvascular obstruction after primary angioplasty: a study performed with contrast-enhanced magnetic resonance. J Am Coll Cardiol 2005;46:1229-35.

[39] Terkelsen CJ, Sørensen JT, Maeng M, et al. System delay and mortality among patients with STEMI treated with primary percutaneous coronary intervention. JAMA 2010;304:763-71.

[40] Terkelsen CJ, Jensen LO, Tilsted HH, et al. Health care system delay and heart failure in patients with ST-segment elevation myocardial infarction treated with primary percutaneous coronary intervention: follow-up of population-based medical registry data. Ann Intern Med 2011;155:361-7.

[41] Assessment of the Safety and Efficacy of a New Treatment Strategy with Percutaneous Coronary Intervention (ASSENT-4 PCI) investigators. Primary versus tenecteplase-facilitated percutaneous coronary intervention in patients with ST-segment elevation acute myocardial infarction (ASSENT-4 PCI): randomised trial. Lancet 2006;367:569-78.

[42] De Luca G, Marino P. Facilitated angioplasty with combo therapy among patients with ST-segment elevation myocardial infarction: a meta-analysis of randomized trials. Am J Emerg Med 2009 Jul;27(6):683-90. 
[43] De Luca G, Bellandi F, Huber K, et al. Early glycoprotein IIb-IIla inhibitors in primary angioplasty-abciximab long-term results (EGYPT-ALT) cooperation: individual patient's data meta-analysis. J Thromb Haemost Dec 2011;9(12):2361-70.

[44] Van't Hof AW, Ten Berg J, Heestermans T, et al. Ongoing Tirofiban In Myocardial infarction Evaluation (On-TIME) 2 study group. Prehospital initiation of tirofiban in patients with ST-elevation myocardial infarction undergoing primary angioplasty (On-TIME 2): a multicentre, double-blind, randomised controlled trial. Lancet Aug 16 2008;372(9638):537-46.

[45] De Luca G. Glycoprotein IIb-IIla inhibitors. Cardiovasc Ther Oct 5 2011, http: //dx.doi.org/10.1111/j.1755-5922.2011.00293.x [Epub ahead of print].

[46] Ellis SG, Tendera M, de Belder MA, et al. Facilitated PCI in patients with ST-elevation myocardial infarction. N Engl J Med 2008 May 22;358(21):2205-17.
[47] Sinusas AJ, Shi Q, Vitols PJ, et al. Impact of regional ventricular function, geometry, and dobutamine stress on quantitative ${ }^{99 \mathrm{~m}} \mathrm{Tc}-$ sestamibi defect size. Circulation 1993;88:2224-34.

[48] Migliorini A, Stabile A, Rodriguez AE, et al. Comparison of AngioJet rheolytic thrombectomy before direct infarct artery stenting with direct stenting alone in patients with acute myocardial infarction. The JETSTENT trial. J Am Coll Cardiol 2010;56:1298-306

[49] Shewan LG, Coats AJ. Ethics in the authorship and publishing of scientific articles. Int J Cardiol 2010;144:1-2. 